\title{
Paediatric inpatient utilisation in a district general hospital
}

Y Thakker, T A Sheldon, R Long, R MacFaul

\begin{abstract}
Paediatric inpatient utilisation in a district general hospital was studied for 20 general practices covering a population of 26433 children. The factors influencing the rate and route of admission (general practitioner (GP) or accident and emergency department) were analysed for 894 emergency non-traumatic admissions over a 12 month period.
\end{abstract}

The overall rate of acute, nontraumatic admission was $33.8 / 1000 ; 35 \%$ of these admissions were via the accident and emergency department. Asthma was the most common reason for admission $(16 \cdot 1 \%) ; 56.9 \%$ of the admissions resulted from respiratory tract illness and $44 \%$ were for an infective illness.

There was a significant variation in the route and rate of admission across practices. Admission rates ranged from 10 to $70 / 1000$ children under 15 and the proportion via the accident and emergency department from $19 \%$ to $85 \%$. The proportion of admissions via the accident and emergency department for each practice was highly negatively correlated with the number of GPs in the practice, the number of children under 15 registered, and positively correlated with the unemployment rate attributed to the list. Using multiple logistic regression analysis, the risk of being admitted via the accident and emergency department relative to GP admission was shown to be higher for older children (odds ratio for each year of age 1.05) and less for children registered with large practices with more GPs (odds ratio for each extra GP 0.36) or practices with more children under 15 (odds ratio per extra child 0.9991). Access to hospital as measured by isochrone bars and social characteristics of the ward of residence of each child admitted were not associated with the route of admission.

The admission rate for each practice was positively, but not statistically significantly, associated with the unemployment rate attributed to the list, the unemployment rate of the ward where the practice was located, and the percentage of admissions via accident and emergency, and negatively associated with the percentage of the list under 15 years. (Arch Dis Child 1994; 70: 488-492)

Correspondence to: Dr Y Thakker, Milton Keynes General Hospital, Standing Way, Eaglestone, Milton Keynes MK6 5LD.

Accepted 23 February 1994

Hospital admissions in childhood have increased over the past $10-15$ years. ${ }^{1-5}$ Various explanations have been advanced: the increased availability of beds because of the decreasing lengths of stay; changing technology; increased patient expectation ${ }^{6}$; improved paediatric training for general practitioners $(\mathrm{GPs})^{3}$; and changing patterns of admission for childhood asthma. ${ }^{7} 8$

Admission rates for disorders which have contributed most to the increase in paediatric admissions (asthma, upper respiratory tract infections, and gastrointestinal diseases) ${ }^{1}$ show large geographical variations. ${ }^{9}$ The variations may partly result from the referral and admission process - that is, via the GP or self referral to the accident and emergency department limiting the control over hospital use by the GP. Between $4 \%{ }^{10}$ and $7 \%{ }^{11}$ of children attending a children's accident and emergency department were referred for outpatient opinion and between $11 \%^{10}$ and $14 \%^{11}$ were admitted.

There is little information on the referral patterns of paediatric admissions and on the variation in use of acute paediatric inpatient services by GPs. This paper reports the results of a population based study aimed at identifying factors influencing the route of admission and the rate of admission by GPs.

\section{Methods}

Data were taken from an extract of the Wakefield district information services. All children, aged 0-15 years, admitted as medical emergencies via GPs and accident and emergency departments between 1 January 1990 and 31 December 1990 were identified. For each child the diagnosis, route of admission, postcode of residence, and GP were identified. Diagnostic coding analysis showed the range of disorders for which children were admitted by each route. Those with an $\mathrm{E}$ code diagnosis that is, an external cause (such as head injury and accidental ingestion) - were excluded as presentation to the accident and emergency department for this reason was clearly appropriate.

Data on children resident in Wakefield but admitted to neighbouring hospitals were

Table 1 Summary of study population

\begin{tabular}{lll}
\hline Population & Total No & Aged 0-15 years \\
\hline Wakefield DHA & 145820 & 28520 \\
Wakefield DHA practices† & 141048 & 26433 \\
Catchment population & & \\
$\quad \begin{array}{ll}\text { All acute specialties } \\
\text { Paediatrics }\end{array}$ & 209000 & - \\
\hline
\end{tabular}


obtained from the regional information services but details of the GP were not available for most of these children and they were not included in the final analysis. Analysis of Wakefield District Health Authority area general practices was carried out. The population data showed that these practices have registered with them $93 \%$ of the Wakefield District Health Authority population aged 0-15 years (table 1 ). The Wakefield District Health Authority practice population was used because it allowed a population based analysis.

For each practice the total number of admissions was analysed by route of admission and proportion of total admissions which occurred via the accident and emergency department. Data on practice characteristics were obtained from the Family Health Services Authority (FHSA).

Social characteristics for each ward were derived from the 1991 census and were linked via the postcode to each child admitted. The unemployment rate and the Jarman underprivileged area score for the electoral ward in which each practice was located were also recorded. An attributed unemployment rate for the list of each general practice was obtained from the FHSA. This was calculated as a weighted average of the unemployment rate of each enumeration district weighted by the number of people registered with each practice in each enumeration district. Attributed rates of other social characteristics from the census were not available. The social characteristics of the ward in which the practice was based were used as proxies for the socioeconomic profile of the practice population. An average of $52 \%$ of all admissions were resident in the same electoral ward as the practice (range $30 \%$ to $100 \%$ ), the central town practices having the lower figures.

Accessibility to the hospital by private transport from the different electoral wards was assessed by the method described by the University of York Health Economics Consortium. ${ }^{12}$ Areas showing common travel times (isochrone bars) were determined. By superimposing the isochrone map onto an electoral ward map of the Wakefield District Health Authority and using Office of Population Censuses and Surveys census data on populations, the proportions of the population in approximate travel time bands was established. The weighted travel time for each electoral ward was then calculated. These ranged from five minutes to over 23 minutes.

Table 2 Acute medical paediatric (0-15 years) admissions to Pinderfields Hospital (1990). Total paediatric admissions 2069, of which 1645 (79.5\%) were emergencies

\begin{tabular}{lccccc}
\hline & No of & & \multicolumn{2}{l}{ Non-traumatic admissions } \\
\cline { 5 - 6 } Route of admission & admissions & $\begin{array}{l}\text { Admissions } \\
\text { with E code }\end{array}$ & Total & Wakefield DHA \\
\hline Accident and emergency department & 845 & 367 & 478 & 318 \\
GP & 800 & 16 & 784 & 576 \\
Total & 1645 & 383 & 1262 & 894 \\
\hline
\end{tabular}

DHA $=$ District Health Authority.
ANALYSIS

Confidence intervals (95\%) for the admission rates and the proportion admitted via accident and emergency departments were calculated assuming Poisson and binomial distributions respectively, using the software package 'Confidence with statistics'. ${ }^{13}$

The proportion of admissions via accident and emergency departments for each general practice was explored by multiple linear regression on a range of practice characteristics and social variables for the practice. Variables which were not significant at the $5 \%$ level were removed in a stepwise manner. For children admitted to hospital, the risk of being admitted via the accident and emergency department compared with GP admission was modelled using multiple logistic regression. Modelling used a backward manual stepwise approach which included all the available individual social data based on the ward of residence and practice characteristics. Variables which were not significant at the $5 \%$ level were removed in a stepwise manner. Children admitted by the two routes in one year were omitted in this part of the analysis and multiple admissions via one route were treated as a single admission as they do not contain independent information.

The variation in practice rates of admission was analysed by simple correlation and linear regression using the package SPSS. The GP practice, socioeconomic, and access characteristics were used as explanatory variables. The practice characteristics included the number of GPs, the population and the percentage of the population under 15 years of age registered, the total list size and the attributed unemployment rate, and the unemployment rate and Jarman underprivileged score of the ward in which the practice was located.

\section{Results}

A total of 2069 paediatric medical admissions occurred over the 12 month period. A total of $1645(79.5 \%)$ of these were admitted as emergencies via the GP or the accident and emergency department. Three hundred and eighty three $(23.3 \%)$ of all the emergency admissions resulted from trauma (head injury or accidental ingestion) and were excluded from the analysis. Three of the remaining 1262 children with an acute non-traumatic medical illness could not be allocated to a practice, one was not registered with a GP, and the medical records were unobtainable for two. Of the remainder, $894(71 \cdot 2 \%)$ came from the Wakefield District Health Authority practices. Table 2 summarises these data.

The 894 admissions analysed occurred in 755 children. Six hundred and forty nine were admitted once only; the remaining 106 children accounted for 245 admissions with 21 children $(2 \cdot 8 \%$ of the children admitted $)$ having three or more admissions (accounting for $8.2 \%$ of all admissions). For children under the age of 2 years such multiple admissions occurred in $17 \%$, accounting for $32 \%$ of the admissions in this age group. This pattern has been observed in another study. ${ }^{14}$ Forty one 
Table 3 Diagnostic codes and route of admission

\begin{tabular}{lccc}
\hline & & \multicolumn{2}{c}{ Route of admission (\%) } \\
\cline { 3 - 4 } & $N o(\%)^{\star}$ & $\begin{array}{l}\text { Via accident and } \\
\text { emergency department }\end{array}$ & Gia \\
Diagnosis (ICD codes) & $(n=894)$ & $73 \cdot 2$ & $26 \cdot 8$ \\
\hline Febrile convulsion (780.3) & $41(4 \cdot 6)$ & $53 \cdot 8$ & $46 \cdot 2$ \\
Otitis media (382) & $13(1 \cdot 5)$ & $50 \cdot 0$ & $50 \cdot 0$ \\
Constipation (564) & $12(1 \cdot 3)$ & $38 \cdot 5$ & $61 \cdot 5$ \\
URTI (460-465) & $91(10 \cdot 2)$ & $37 \cdot 2$ & $62 \cdot 8$ \\
Viral infection (078-079) & $78(8 \cdot 7)$ & $36 \cdot 1$ & $63 \cdot 9$ \\
Asthma (493) & $144(16 \cdot 1)$ & $31 \cdot 8$ & $68 \cdot 2$ \\
Gastroenteritis (003-009, 558) & $44(4 \cdot 9)$ & $30 \cdot 0$ & $70 \cdot 0$ \\
Breathing difficulties (786) & $30(3 \cdot 3)$ & $29 \cdot 2$ & $70 \cdot 8$ \\
Bronchiolitis (466) & $48(5 \cdot 4)$ & $20 \cdot 0$ & $80 \cdot 0$ \\
Vomiting (787) & $30(3 \cdot 4)$ & $14 \cdot 3$ & $84 \cdot 7$ \\
Meningitis (320, 322, 047) & $21(2 \cdot 3)$ & $15 \cdot 4$ & $88 \cdot 5$ \\
Pneumonia (480-486) & $39(4 \cdot 4)$ & $11 \cdot 5$ & $91 \cdot 0$ \\
Failure to thrive/feeding problem (783) & $26(2 \cdot 9)$ & $9 \cdot 0$ & $100 \cdot 0$ \\
Pyloric stenosis (750.5) & $11(1 \cdot 2)$ & 0 & $58 \cdot 6$ \\
UTI (599) & $17(1 \cdot 9)$ & $41 \cdot 4$ & \\
Others & $249(28 \cdot 1)$ & & \\
& & & \\
\hline
\end{tabular}

URTI= upper respiratory tract infection; UTI= urinary tract infection.

$\star$ Percentage of all admissions.
Table 5 Logistic regression model of risk of admission via accident and emergency department relative to number of GPS in the practice

\begin{tabular}{lclll}
\hline Variable & $\begin{array}{l}\text { Coefficient } \\
(\beta)\end{array}$ & $\begin{array}{l}\text { Standard } \\
\text { error }\end{array}$ & $\begin{array}{l}\text { Statistical } \\
\text { significance } \\
\text { of coefficient }\end{array}$ & $\begin{array}{l}\text { Odds } \\
\text { ratio }\end{array}$ \\
\hline $\begin{array}{l}\text { Age on admission } \\
\text { Number of GPs }\end{array}$ & 0.0456 & 0.020 & 0.025 & 1.047 \\
$\begin{array}{l}\text { Practice code } \\
\text { Constant }\end{array}$ & 3.0342 & 0.509 & $\begin{array}{l}0.04 \\
0.0311\end{array}$ & 0.3555 \\
& & 2.11 & 0.09 & \\
\end{tabular}

practices to Pinderfields Hospital for acute non-traumatic illness was $33 \cdot 8 / 1000$. Thirty five per cent of these admissions were via the accident and emergency department. Table 4 shows that there was significant variation in the rates and route of admission among the 20 practices. Data on the size and number of admissions for each practice are not included to maintain the anonymity of the practices. The practice child population ( $0-15$ years) ranged from 200 to 2419 , with a mean of 1322 and a median of 1369 . One of the practices was very small, had unusual characteristics with a high proportion of children under 15 years, and was excluded from further analysis.

The proportion of admissions which occurred via the accident and emergency department for each practice was highly negatively correlated with the number of GPs in the practice $(r=-0.72 ; \mathrm{p}<0.001)$ and the population under 15 years $(r=-0.7 ; \mathrm{p}<0.001)$, and was positively correlated with the attributed unemployment rate of the list $(r=0.64$; $\mathrm{p}<0.01)$. Multiple regression analysis resulted in the best model being:

$\%$ Admitted via accident and emergency $=-0 \cdot 16+0 \cdot 064$ Unemployment $-1.5 \times 10^{-4}$ Population $<15$ years $\left(R^{2}=0.59\right)$ $(p=0.06)$ $(p=0.02)$

Using multiple logistic regression, the risk of being admitted via the accident and emergency department relative to GP admission was shown to be higher for older children (odds ratio for each year of age $1.05 ; p=0.003$ ) and less for children registered with a practice having more GPs (odds ratio for each extra GP $0.36 ; p=0.042$ ) (table 5). Independent of these two variables, a further factor for general practice was also statistically significant in explaining the variation in route of admission. This means that one or more unidentified characteristics that distinguish practices are associated with the likelihood of admission via accident and emergency. Access to hospital, as measured by the weighted travel time, was not associated with the route of admission. This model shows a high sensitivity of the odds of admission via accident and emergency to the number of GPs. Thus in going from a practice of three to one of six GPs decreases the odds by a factor of 22. Repeating the analysis, an equally good model replaces 'the number of GPs' with 'the number of children under 15 years of age' with an odds ratio of 0.9991 $(p<0.0001)$, indicating that for every 100 extra children in a practice the odds of admission via accident and emergency decreases by 0.09 (table 6). 
Table 6 Logistic regression model of risk of admission via accident and emergency department relative to number of children aged $<15$ years in practice

\begin{tabular}{|c|c|c|c|c|}
\hline Variable & $\begin{array}{l}\text { Coefficient } \\
(\beta)\end{array}$ & $\begin{array}{l}\text { Standard } \\
\text { error }\end{array}$ & $\begin{array}{l}\text { Statistical } \\
\text { significance } \\
\text { of coefficient }\end{array}$ & $\begin{array}{l}\text { Odds } \\
\text { ratio }\end{array}$ \\
\hline $\begin{array}{l}\text { Age on admission } \\
\text { Population under } 15 \text { years in practice } \\
\text { Constant }\end{array}$ & $\begin{array}{r}0.048 \\
-0.001 \\
0.928\end{array}$ & $\begin{array}{l}0.021 \\
0.0002 \\
0.26\end{array}$ & $\begin{array}{l}0.02 \\
0.000 \\
0.000\end{array}$ & $\begin{array}{l}1.049 \\
0.999\end{array}$ \\
\hline
\end{tabular}

The rate of admission of children by practice was positively associated with the attributed unemployment rate of patients registered with the practice $(r=0 \cdot 24)$, the unemployment rate of the ward where the practice was located $(r=0.39)$, and the percentage of admissions via accident and emergency $(r=0 \cdot 15)$ and negatively associated with the percentage of the list under 15 years of age $(r=-0 \cdot 3)$. The latter association is in contrast with the review outpatient attendance rate per practice reported in a previous study. ${ }^{15}$ None of these was statistically significant at the $5 \%$ level, however. This is most probably due to the lack of power because of the small number of practices (19) in the analysis. The relation with the Jarman 8 underprivileged area score for the ward where the practice was based $(r=0 \cdot 27)$ was less strong than for unemployment rate. Multiple linear regression of the rate of admission against all the social and practice characteristic variables produced no significant result.

\section{Discussion}

This study provides information on the use of paediatric inpatient services in a well defined population which is distributed over a fairly dense urban and surrounding semirural area. The hospital has 19 paediatric medical beds and 20 paediatric surgical beds. Referrals for admission from GPs and the accident and emergency department are received by the senior house officer on call and are accepted if there is an available bed, the threshold for admission being determined by the source of referral. It is departmental policy to admit any child under the age of 5 years who presents to the accident and emergency department after 9 pm.

The proportion of admissions for each practice via the accident and emergency department ranged from $19 \%$ to $85 \%$. This route is appropriate for children with traumatic injuries or serious illnesses needing urgent medical attention. The former were excluded from the analysis and the latter are uncommon. For most children this route of admission was inappropriate and in some cases could have resulted in an unnecessary admission by virtue of presenting after $9 \mathrm{pm}$.

This study shows that the variation in the proportion of children admitted via accident and emergency is significantly inversely associated with the size of the practice (number of GPs and children under 15 years). This may reflect the actual or perceived availability of the GP, which have been identified as important reasons for self referral to the accident and emergency department. ${ }^{1011} 1617$ Larger practices may offer greater accessibility through longer surgery hours, more flexibility in providing urgent appointments and visits, out of hours (emergency) services, and increased promotion/patient education through practice information leaflets.

Of interest is the finding that the social characteristics of the ward of residence of children admitted was not associated with the route of admission, though the attributed unemployment rate for each practice list is positively associated with the proportion of children admitted via accident and emergency in the practice. In other words the individual and the practice based analysis of the factors influencing the route of admission, although agreeing on the importance of the size of the practice, differed with respect to the importance of social factors. The social characteristics of wards are likely to be poor proxies for the characteristics of individual children from that ward who are admitted to hospital. This is because wards are large and usually heterogenous, thus children admitted to hospital are unlikely to be representative of the ward (the ecologic problem). The attributed ward unemployment rate, being based on the smaller and less heterogenous enumeration districts, is likely to be a more accurate reflection of the average characteristics of the people registered with a GP, but not necessarily of families with children registered or children admitted.

Proximity and easy access to the hospital have been identified as being important factors contributing to the inappropriate use of the accident and emergency department ${ }^{18-20}$; this was not confirmed in this study after adjusting for other factors.

The overall acute, non-traumatic admission rate per 1000 child practice population was 33.8. Reported rates from previous studies include $30 \cdot 9 / 1000$ and $21 \cdot 9 / 1000$. Direct comparison with the previously reported studies $^{1-5}$ is limited because of the variable inclusion of accidental ingestion and head injuries. Significant variation was observed between general practice admission rates per 1000 child population ranging from 10 to 70 . The analysis did not successfully explain much of this variation but suggests that, in addition to chance, the variation may be affected by practice characteristics (number of children under 15) and socioeconomic factors (such as unemployment rates). Because of the small number of practices, however, there was little statistical power to explore these potential relations.

Higher rates of admission to hospital in poorer areas may be due to the increased prevalence of certain disorders combined with a lowered threshold for admission. The relation between poverty and sickness has been well described, 2122 but the actual factors contributing to it need to be understood. The fact that the unemployment rate of the ward in which the practice was based was more strongly associated with the rate of admission than the attributed rate for the list may have no significance, but is of interest. Whether this reflects some ecologic problems or something 
more interesting about the influence of practice location is not possible to explore further in this study, but may be worth further investigation.

The extent to which differences in GP referral behaviour might account for the variation in admission rate for each practice is unclear. Studies of paediatric outpatient referral patterns suggest that this may vary according to the experience/interest of the GP. ${ }^{15}$ The paediatric experience and training of GPs may heighten their awareness of the risks of serious illnesses contributing to a lowered threshold for admission. ${ }^{23}$ The emphasis of both the Court report ${ }^{23}$ and a follow up report, ${ }^{24}$ however, has been on the provision of child health services outside the hospital, with particular emphasis on improvement of the primary care of the children. In a study from the USA $13 \%$ of patient days in general paediatrics were judged to be inappropriate. ${ }^{25} \mathrm{~A}$ study on the appropriateness of self referrals and referrals for admission from GPs has been undertaken in Wakefield and will be reported elsewhere.

Reduction in some of the variations in admission rate may be possible with an experienced paediatric specialist screening some admissions, by GPs working in an accident and emergency department, ${ }^{26}$ and by encouraging parents into the appropriate use of primary care services. It is likely, however, that further reduction in variations may need to be accompanied by reductions in the inequalities in socioeconomic factors and their consequent effect on the health of children. More research is needed to explore the complex and interactive effects of social conditions and practice characteristics and behaviour on the rate and route of admissions.

We acknowledge the useful advice of the two anonymous referees and the assistance of Alex Watt of the York Health Economics Consortium in showing how to construct isochrone measures.

1 Hill AM. Trends in paediatric medical admissions. $B M 7$ 1989; 298: 1479-83.

2 Forfar JO. Trends in paediatric medical admissions. BMF 1989; 298: 1711 .
3 Durojaiye L, Hutchison T, Madeley R. Improved primary care does not prevent the admission of children to hospital. Public Health 1989; 103: 181-8.

4 Thornes R. Where are the children? Report of joint working group of BPA, NAWCH, RCH. London: Caring for Children in the Health Services, 1987.

5 Wadsworth MEJ. Follow up of the first national birth cohort findings from the Medical Research Council. National findings from the Medical Research Council. National
Survey of Health and Development. Paediatric and Survey of Health and Development.

6 Maynard A. Logic in medicine: an economic perspective. $B M \mathcal{F}$ 1987; 295: 1537-41.

7 Knot A, Burn R, Evans N, Lenney C, Lenney V. Seasonal variations and time trends in childhood asthma in England and Wales 1975-81. BMF 1984; 289: 235-8.

8 Anderson HR. Increase in hospital admissions for childhood asthma: trends in referral, severity and readmissions from 1970 to 1985 in a health region of the United Kingdom. 1970 to 1985 in a health
Thorax 1989; 44: 614-9.

9 Wennberg JE, McPherson K, Caper P. Will payment based on diagnostic related groups control hospital costs? $N$ Engl f Med 1984; 311: 295-300

10 Bedford HE, Jenkins SM, Shore C, Kenny PA. Use of an east end children's accident and emergency departmen for infants: a failure of primary health care? Quality in Health Care 1992; 1: 29-33.

11 Bowling A, Isaacs D, Armstrong J, Roberts JE, Elliott EJ. Patient use of a paediatric hospital casualty department in the east end of London. Family Practice 1987; 4: in the 90 .

12 Watt A. Future role of district health. Assessing needs for services and setting priorities. University of York: York Health and setting priorities. University of York: York

13 Gardner MJ, Altman DG. Statistics with confidence. London: BMJ Publishing Group, 1989.

14 Spencer NJ, Lewis MA. Multiple admissions under 2 year of age. Arch Dis Child 1991; 66: 938-40.

15 MacFaul R, Long R. Paediatric outpatient utilisation in district general hospital. Arch Dis Child 1992; 67: 1068-72.

16 Horder E. Inappropriate use of casualty departments. $\mathcal{F} R$ Coll Gen Pract 1988; 38: 372

17 Singh S. Self referral to accident and emergency departments: patients perceptions. BMF 1988; 297: 1179-80

18 McKee CM, Gleadhill DNS, Watson JD. Accident and emergency rates: variations among patients from different general practices. $\Im R$ Coll Gen Pract 1990; 40 150-3.

19 Roghman KJ, Zastowny TR. Proximity as a factor in the selection of health care provider. Soc Sci Med 1979; 13D 61-9.

20 Ingram DR, Clark DR, Murdie RA. Distant and decision to visit an emergency department. Soc Sci Med 1978; 12: 55-62.

21 MacLure A, Stewart GT. Admission of children to hospital in Glasgow: relation to unemployment and other deprivation variables. Lancet 1984; ii: 682-5.

22 Black D, Morris JN, Townsend P, Smith C. Inequalities in health. London: Department of Health and Social Security, 1980 .

23 Committee on Child Health Services. Fit for the future. London: HMSO, 1976. (Court report.)

24 Graham P. Investing in the future: child health ten years afier the Court report. London: Policy and Practice Review Group, National Children's Bureau, 1987.

25 Kemper KJ. Medically inappropriate hospital use in a paediatric population. $N$ Engl $f$ Med 1988; 318: 1033-7.

26 National Audit Office. NHS accident and emergency departments in England: National Audit Office report. London: HMSO, 1992. (House of Commons Paper, 1 August 1992.) 